Superalloys 2012: 12 ${ }^{\text {th }}$ International Symposium on Superalloys

\title{
ON THE DEVELOPMENT OF CAST ATI 718PLUS® ALLOY FOR STRUCTURAL GAS TURBINE ENGINE COMPONENTS
}

\author{
Benjamin Peterson ${ }^{1}$, Dan Frias ${ }^{1}$, Dave Brayshaw ${ }^{2}$, Randy Helmink ${ }^{3}$, Scott Oppenheimer ${ }^{4}$, Eric Ott $^{5}$, Ray Benn ${ }^{6}$, Michael Uchic $^{7}$ \\ ${ }^{1}$ Honeywell Aerospace; 111 S. $34^{\text {th }}$ Street; Phoenix, AZ 85034, USA \\ ${ }^{2}$ PCC Structurals; 4600 SE Harney Dr, Portland, OR 97206, USA \\ ${ }^{3}$ Rolls-Royce; 2001 South Tibbs Ave, Indianapolis, IN 46241, USA \\ ${ }^{4}$ ATI Allvac; 2020 Ashcraft Ave, Monroe, NC 28111, USA \\ ${ }^{5}$ GE Aviation; 1 Neumann Way, Cincinnati, OH 45215, USA \\ ${ }^{6}$ Pratt \& Whitney; 400 Main Street, E. Hartford, CT 06108, USA \\ ${ }^{7}$ AFRL/RXLM, $223010^{\text {th }}$ Street, Wright-Patterson AFB, OH 45433, USA
}

Key Words: ATI 718Plus®, Castability, Weldability, Mechanical Properties

\begin{abstract}
Significant effort has been exerted to develop a cast version of the ATI 718Plus ${ }^{\circledR}$ alloy for aerospace applications with use temperatures approximately $42^{\circ} \mathrm{C}\left(75^{\circ} \mathrm{F}\right)$ higher than conventional alloy 718. Current alternatives to alloy 718 for low cost, hightemperature investment-cast structural components are limited. The target technology application is gas turbine structural components, including combustor plenums, stator cases, diffuser cases, turbine cases, turbine frames, and various other highstrength/high-temperature structural castings. An overview of the results from the castability and weldability studies, compositional selection and heat treatment selection, select mechanical properties, and cast component trials will be discussed.
\end{abstract}

718 Plus is a registered trademark of and 718Plus ${ }^{\circledR}$ alloy is a patented proprietary alloy ATI Properties, Inc.

\section{Introduction}

The Metals Affordability Initiative (MAI) program has exerted significant effort to develop a cast version of the ATI 718Plus ${ }^{\circledR}$ alloy. As modern gas turbine engine component temperatures continue to increase, the utility of conventional alloy 718 is being exhausted. Conventional alloy 718 is limited in temperature capability to $649^{\circ} \mathrm{C}\left(1200^{\circ} \mathrm{F}\right)$ due to the stability of its principal strengthening precipitate, $\gamma$ ". Above $649^{\circ} \mathrm{C}\left(1200^{\circ} \mathrm{F}\right)$, alloy 718 is thermodynamically unstable. The $\gamma$ " $\left(\mathrm{Ni}_{3}[\mathrm{Nb}, \mathrm{Al}, \mathrm{Ti}]\right)$ phase transforms to the equilibrium $\delta\left(\mathrm{Ni}_{3} \mathrm{Nb}\right)$ phase, which has an associated debit in mechanical properties and performance [1]. Current alternatives to alloy 718 for low cost, high-temperature investment-cast structural components are limited and will challenge future cost targets for the industry. The objective of the MAI program is to investigate and enable the use of 718Plus ${ }^{\circledR}$ alloy in the form of investment castings by (1) increasing the allowable operating temperature by about $42^{\circ} \mathrm{C}\left(75^{\circ} \mathrm{F}\right)$ as compared with conventional cast alloy 718 and (2) achieve approximately 25 percent cost savings as compared with cast Waspaloy. Gas turbine structural components is the target technology application, including the manufacture of combustor plenums, stator cases, diffuser cases, turbine cases, turbine frames, and various other high-strength/high-temperature structural castings.

A significant portion of the alloy development work for cast 718Plus alloy under the MAI program has been reported and presented [2]. This work included: (1) thermodynamic simulations to virtually test elemental composition effects on key casting parameters such as the liquidus, the solidus, and key phase temperatures and (2) castability trials using hot tear and nonconcentric ring molds to select an optimized composition space (five specific compositions) for (3) weldability (autogenous electron beam welds) and mechanical property (tensile, creep, and fatigue) assessments. This work concluded that all of the five compositions evaluated were castable and weldable. A single target composition was down-selected for further evaluation. Table 1 contains the nominal, down-selected composition. The nominal heat treat includes $\mathrm{HIP}$ after casting, $982^{\circ} \mathrm{C}\left(1800^{\circ} \mathrm{F}\right)$ solution, and a two step age at $788^{\circ} \mathrm{C}\left(1450^{\circ} \mathrm{F}\right)$ for 8 hours and $704^{\circ} \mathrm{C}\left(1300^{\circ} \mathrm{F}\right)$ for 8 hours. Figure 1 and 2 contain the geometric mean tensile and creep properties, respectively. This paper reports the results and findings from the (1) heat treat optimization, (2) detailed mechanical property assessments, and (3) trial part casting tasks of the MAI program.

Table 1: Down-selected nominal composition:

\begin{tabular}{|c|c|}
\hline Element & Nominal (wt\%) \\
\hline $\mathrm{Ni}$ & Bal. \\
\hline $\mathrm{Cr}$ & 18.0 \\
\hline $\mathrm{Co}$ & 9.1 \\
\hline $\mathrm{Mo}$ & 2.7 \\
\hline $\mathrm{W}$ & 1.0 \\
\hline $\mathrm{Nb}$ & 6.5 \\
\hline $\mathrm{Al}$ & 1.45 \\
\hline $\mathrm{Ti}$ & 0.75 \\
\hline $\mathrm{Fe}$ & 9.0 \\
\hline $\mathrm{C}$ & 0.06 \\
\hline $\mathrm{P}$ & 0.006 \\
\hline $\mathrm{B}$ & 0.005 \\
\hline
\end{tabular}




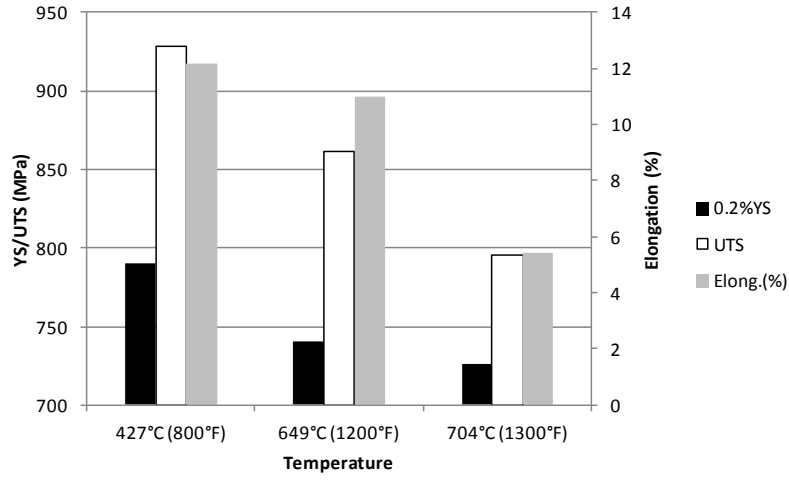

Figure 1: Average tensile values of the down-selected chemistry.

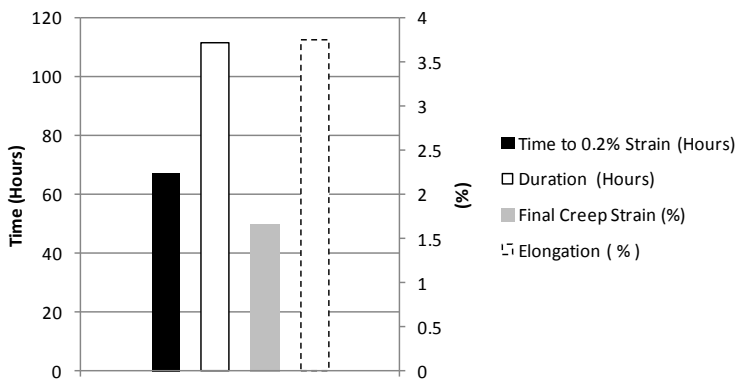

Figure 2: Average creep values, tested at $704^{\circ} \mathrm{C}\left(1300^{\circ} \mathrm{F}\right)$ and 586 $\mathrm{MPa}(85 \mathrm{ksi})$, of the down-selected chemistry.

\section{Experimental}

\section{Heat Treatment Optimization}

A heat treatment optimization evaluation was performed on the down-selected composition. After casting and repair, superalloy castings are typically heat treated by performing (1) a homogenization to evenly diffuse the elements, (2) a $\gamma^{\prime}$ solution, and (3) an aging sequence to form the desired $\gamma^{\prime}$ size and distribution. Sixteen nominally sized coupons were exposed to a range of times $(1,4,8$, and 16 hours) and temperatures (1163, 1177,1191 , and $1204^{\circ} \mathrm{C} / 2125,2150,2175$, and $2200^{\circ} \mathrm{F}$ ) in a conventional atmospheric box furnace. Optical evaluations of the resulting microstructures aided the selection of a homogenization treatment. An additional mechanical property assessment (tensile, creep, and fatigue) was employed to identify a suitable solution and age heat treat schedule.

\section{Detailed Mechanical Property Assessment}

A detailed mechanical property assessment was performed after a suitable heat treatment schedule was chosen for the down-selected chemistry. Testing included tensile, creep, fatigue, fracture toughness, and fatigue crack growth rate. Thermal stability was also evaluated by testing mechanical properties after two exposure periods: $760^{\circ} \mathrm{C}\left(1400^{\circ} \mathrm{F}\right)$ for 500 hours and $732^{\circ} \mathrm{C}\left(1350^{\circ} \mathrm{F}\right)$ for 1000 hours.

The welding conditions were optimized by the casting vendor and then a cast weld ring was used to characterize a series of partial and full welds. Mechanical test coupons were extracted from this cast weld ring to evaluate the baseline cast ring and welded portions via tensile, creep and fatigue.

Table 2 outlines the detailed mechanical property testing performed. The samples were sectioned from nominally-sized cast plates and machined after heat treatment.

Table 2: Detailed Mechanical Property Assessment Test Plan

\begin{tabular}{|c|c|c|c|c|}
\hline $\begin{array}{c}\text { Detailed Mechanical } \\
\text { Testing }\end{array}$ & $\begin{array}{l}\text { No. of } \\
\text { Temps. }\end{array}$ & No. of Conditions & Specimens & Total \\
\hline Tensile & 5 & $\mathrm{~N} / \mathrm{A}$ & 3 & 15 \\
\hline Stress Rupture (combo bar) & 1 & 5 separate $\mathrm{K}_{\mathrm{t}}^{\prime} \mathrm{s}$ & 3 & 15 \\
\hline Creep $(0.2 \%$ and Rupture $)$ & 3 & 6 & 1 & 18 \\
\hline LCF (smooth) & 3 & R-ratio $=0,-1$ & 6 & 36 \\
\hline LCF (notched) & 2 & R-ratio $=0.05,-1$ & 7 & 35 \\
\hline HCF (smooth) & 2 & R-ratio $=0,-1$ & 6 & 24 \\
\hline Fatigue Crack Growth & 1 & R-ratio $=0.05,0.5$ & 2 & 4 \\
\hline Fracture Toughness & 1 & 3 & 5 & 5 \\
\hline $\begin{array}{c}\text { Microstructure Stability } \\
\text { Testing }\end{array}$ & $\begin{array}{l}\text { No. of } \\
\text { Temps. }\end{array}$ & No. of Conditions & Specimens & Total \\
\hline Tensile & 2 & 2 over-aged conditions ${ }^{*}$ & 3 & 12 \\
\hline Creep $(0.2 \%$ and Rupture $)$ & 1 & 2 over-aged conditions ${ }^{*}$ & 6 & 12 \\
\hline LCF (smooth) & 1 & 2 over-aged conditions ${ }^{*}$ & 3 & 6 \\
\hline Weld Assessment & $\begin{array}{l}\text { No. of } \\
\text { Temps. }\end{array}$ & No. of Conditions & Specimens & Total \\
\hline Tensile & 3 & Weld/Base; Base & 5 & 15 \\
\hline LCF & 1 & Weld/Base; Weld only; Base & 16 & 16 \\
\hline Creep & 1 & Weld/Base; Base & 7 & 7 \\
\hline
\end{tabular}

\section{$\underline{\text { Cast Part Validation }}$}

Select parts from the various aero-engine OEM's that represent a range of part size and complexity were cast as validation (see Table 3).

Table 3: List of part types selected by the OEM's for casting

\begin{tabular}{|c|c|}
\multicolumn{1}{c}{ during the MAI program. } \\
\hline Part Type & Part Complexity \\
\hline Diffuser & Medium sized part, highly complex \\
\hline Combustor Case & Small part, medium complexity \\
\hline Exit Guide Vane & Medium sized part, highly complex \\
\hline Combustor Case & Medium sized part, medium complexity \\
\hline $\begin{array}{c}\text { Turbine Rear } \\
\text { Frame }\end{array}$ & Large part, medium complexity \\
\hline
\end{tabular}

\section{Results}

\section{Heat-treat Optimization}

The target versus actual compositions of all the castings that support the presented data is contained in Table 4.

Table 4: Target versus actual casting compositions (wt $\%$ ).

\begin{tabular}{|c|c|c|c|c|c|c|}
\cline { 2 - 7 } \multicolumn{1}{c|}{} & $\mathbf{F e}$ & $\mathrm{Ti}$ & $\mathbf{A l}$ & $\mathbf{N b}$ & $\mathbf{C}$ & $\mathbf{B}$ \\
\hline Target & 9 & 0.75 & 1.45 & 6.5 & 0.06 & 0.005 \\
\hline Actual & $9.2 \pm 0.1$ & $0.76 \pm 0.01$ & $1.28 \pm 0.03$ & $6.62 \pm 0.05$ & $0.06 \pm 0.01$ & $0.0055 \pm 0.0004$ \\
\hline
\end{tabular}

Based on the evaluation of the microstructure, via optical micrographs, a homogenization for eight hours at $1204^{\circ} \mathrm{C}$ $\left(2200^{\circ} \mathrm{F}\right)$ was chosen since the dendritic structure was observed to be removed. Figure 3 shows an example microstructure with a visible dendritic structure $\left(1163^{\circ} \mathrm{C} / 2125^{\circ} \mathrm{F}\right.$ for one hour) and the microstructure processed with the chosen homogenization schedule $\left(1204^{\circ} \mathrm{C} / 2200^{\circ} \mathrm{F}\right.$ for eight hours). The heat-treat optimization plan was developed and executed as indicated by the 
heat treatment sequence listed below and in Table 5. This plan includes a combination of pre-solutions, solution temperatures, and aging conditions.

Heat Treatment Sequence:

1. HIP after casting

2. Homogenization (all samples)

- $1204^{\circ} \mathrm{C}\left(2200^{\circ} \mathrm{F}\right)$ for 8 hours; furnace cool

3. Heat Treat Schedule

- Pre-solution: $843^{\circ} \mathrm{C}\left(1550^{\circ} \mathrm{F}\right)$ for 16 hours; furnace cool

- Solution: At temperature for 1 hour; gas fan cool

- Standard Age: $788^{\circ} \mathrm{C}\left(1450^{\circ} \mathrm{F}\right)$ for 8 hours; cool at $56^{\circ} \mathrm{C}$ $\left(100^{\circ} \mathrm{F}\right)$ per hour to $704^{\circ} \mathrm{C}\left(1300^{\circ} \mathrm{F}\right)$; hold for 8 hours; furnace cool

- Modified Age: $788^{\circ} \mathrm{C}\left(1450^{\circ} \mathrm{F}\right)$ for 2 hours; cool at $56^{\circ} \mathrm{C}$ $\left(100^{\circ} \mathrm{F}\right)$ per hour to $732^{\circ} \mathrm{C}\left(1350^{\circ} \mathrm{F}\right)$; hold for 4 hours; furnace cool
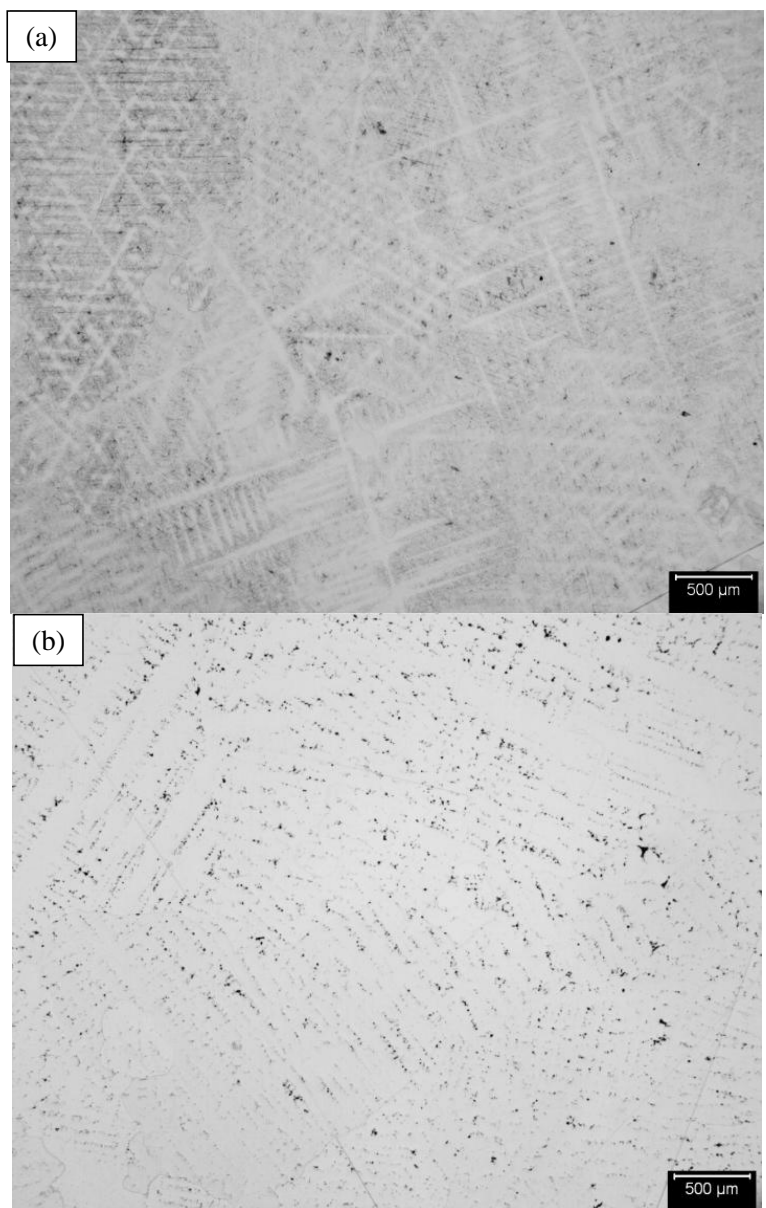

Figure 3: (a) An example microstructure with a visible dendritic structure $\left(1163^{\circ} \mathrm{C} / 2125^{\circ} \mathrm{F}\right.$ for one hour) and (b) the microstructure processed with the chosen homogenization schedule $\left(1204^{\circ} \mathrm{C} / 2200^{\circ} \mathrm{F}\right.$ for eight hours $)$.
Table 5: Heat treat optimization plan

\begin{tabular}{|c|c|c|c|}
\hline Test & Pre-solution & $\begin{array}{c}\text { Solution Temp. } \\
{ }^{\circ} \mathbf{C}\left({ }^{\circ} \mathbf{F}\right)\end{array}$ & Age \\
\hline 1 & Yes & $941(1725)$ & Standard \\
\hline 2 & Yes & $954(1750)$ & Standard \\
\hline 3 & Yes & $968(1775)$ & Standard \\
\hline 4 & No & $954(1750)$ & Standard \\
\hline 5 & No & $968(1775)$ & Standard \\
\hline 6 & No & $968(1775)$ & Modified \\
\hline 7 & No & $982(1800)$ & Standard \\
\hline
\end{tabular}

Evaluation of the heat treat optimization was via a mechanical property assessment. Tensile, creep rupture, creep - combo bar, and fatigue were performed on each of the seven heat treat conditions at $704^{\circ} \mathrm{C}\left(1300^{\circ} \mathrm{F}\right)$. For all heat treat conditions, the tensile and creep ductilities were low compared with the prior results (Figures 1 and 2). As an example, Figure 4 shows the tensile elongations and reductions in area and Figure 5 shows the final creep strains. Note that the thermal processing for the prior work corresponds to heat treat condition 7 except that the prior work did not include a homogenization cycle.

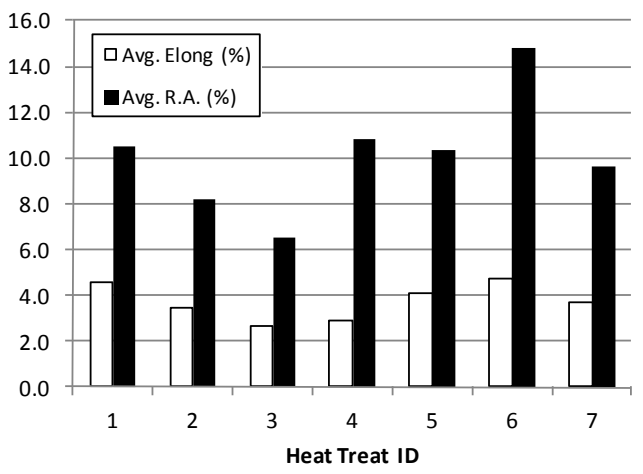

Figure 4: Elevated temperature tensile elongation and reduction in area results from the first round of heat treat optimization heat treatments at $704^{\circ} \mathrm{C}\left(1300^{\circ} \mathrm{F}\right)$.

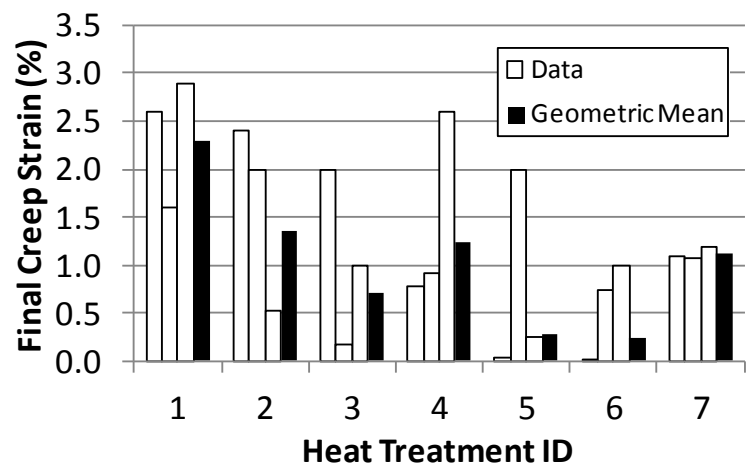

Figure 5: Final creep strain results from tests at $704^{\circ} \mathrm{C}\left(1300^{\circ} \mathrm{F}\right)$ and $586 \mathrm{MPa}(85 \mathrm{ksi})$ from the first round of heat treat optimization evaluation.

It was concluded that the homogenization had a detrimental effect on the properties and that a follow-on evaluation was required. Select heat treatments were again performed, but without the 
homogenization. A substantial increase in tensile and creep ductilities were realized by removal of the homogenization cycle (Figures 6-7)

Figure 8 is a creep fracture surface of a homogenized sample that demonstrates areas of ductile fracture (coalescence of voids dimple structure) and grain boundary separation (smooth surfaces). The grain boundary separation areas exhibit few $\delta$ precipitates on the fracture surface. It can be debated that the alloy creep strength and ductility balance depends on sufficient $\delta$ phase formation on the grain boundary to inhibit grain boundary decohesion, but forming too much $\delta$ phase may reduce $\gamma^{\prime}$ levels excessively.

Microstructures of the homogenized and non-homogenized material are shown in Figure 9, which indicates that more grain boundary delta forms in the HIP+Solution+Age condition. This suggests that extensive compositional diffusion occurs during high time and temperature homogenization. This unfavorably affects mechanical properties.

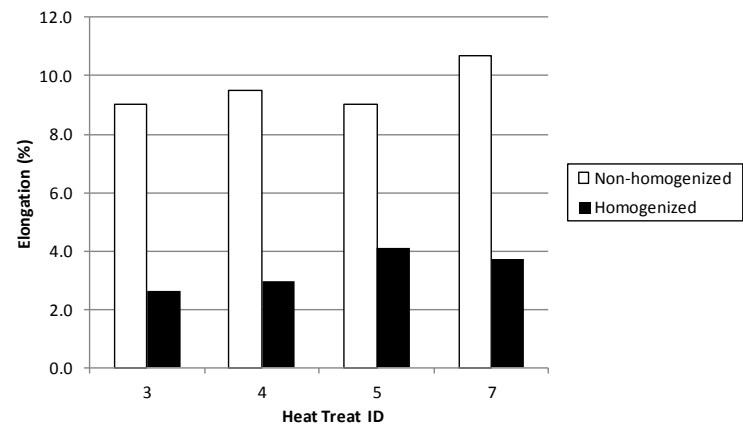

Figure 6: The follow-on heat treat optimization (nonhomogenized) elevated temperature tensile elongation results compared with the homogenized results. Tests performed at $704^{\circ} \mathrm{C}\left(1300^{\circ} \mathrm{F}\right)$.

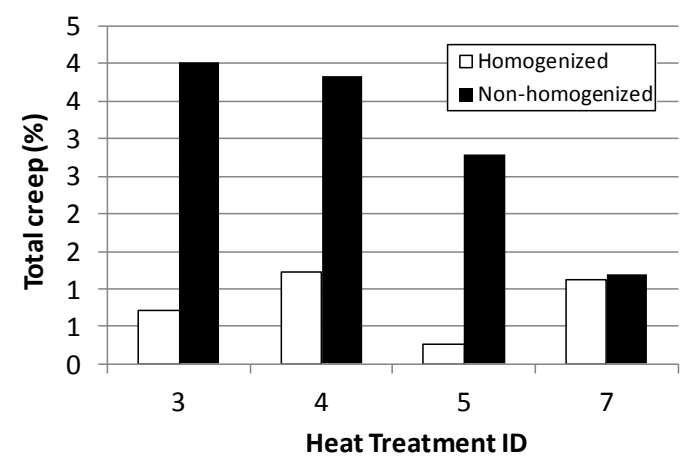

Figure 7: Total creep strain results from tests at $704^{\circ} \mathrm{C}\left(1300^{\circ} \mathrm{F}\right)$ and $586 \mathrm{MPa}(85 \mathrm{ksi})$ from the follow-on heat treat optimization (non-homogenized) and compared with the prior homogenized results for various heat treatments.

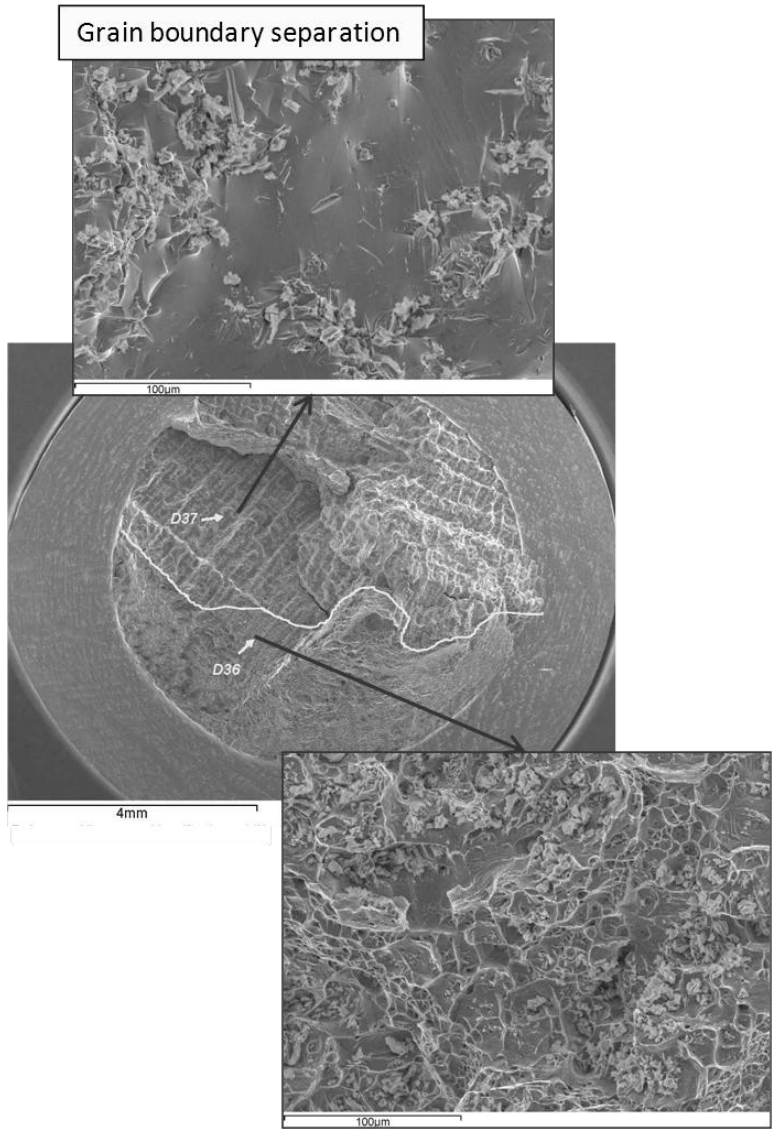

Figure 8: Creep fracture surface of a homogenized sample (secondary electron SEM micrograph). Tested at $704^{\circ} \mathrm{C}\left(1300^{\circ} \mathrm{F}\right)$ and $586 \mathrm{MPa}(85 \mathrm{ksi})$ 

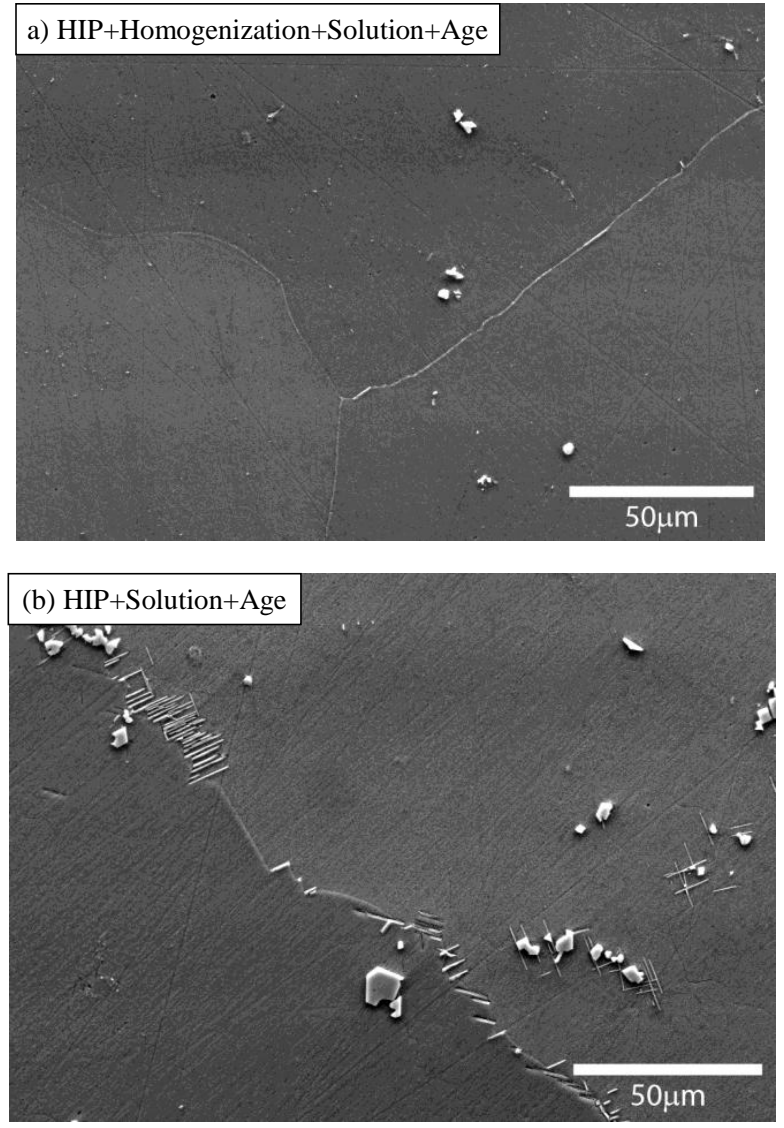

Figure 9: SEM secondary electron images (a) with homogenization and (b) without homogenization.

The tensile, creep rupture, and low cycle fatigue results for the heat treat study without homogenization are summarized in Figures 10-12. Based on these results the heat treatment was chosen for the Detailed Mechanical Property Assessment was HIP; no-homogenization; $968^{\circ} \mathrm{C}\left(1775^{\circ} \mathrm{F}\right)$ for 1 hour, gas fan cool; $788^{\circ} \mathrm{C}\left(1450^{\circ} \mathrm{F}\right)$ for 8 hours, cool to $704^{\circ} \mathrm{C}\left(1300^{\circ} \mathrm{F}\right)$ at $56^{\circ} \mathrm{C}$ $\left(100^{\circ} \mathrm{F}\right)$ per hour, $704^{\circ} \mathrm{C}\left(1300^{\circ} \mathrm{F}\right)$ for 8 hours, furnace cool.

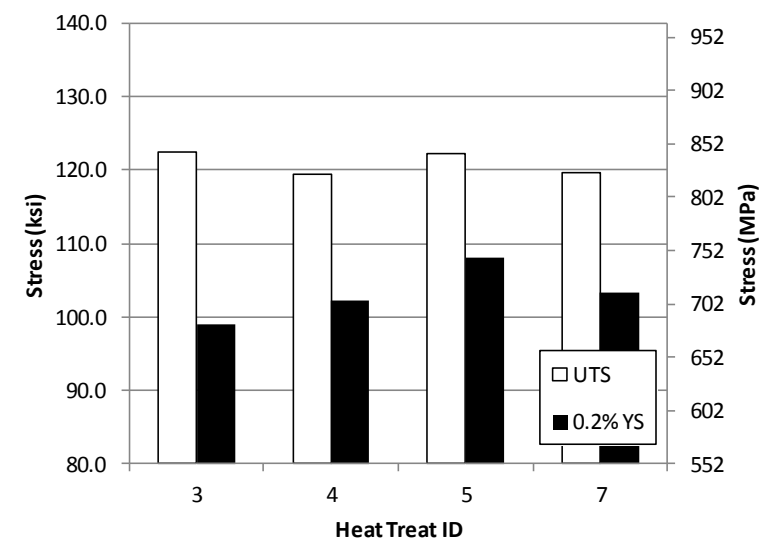

Figure: 10: Yield stress and UTS results for the heat treat study without homogenization, tested at $704^{\circ} \mathrm{C}\left(1300^{\circ} \mathrm{F}\right)$.

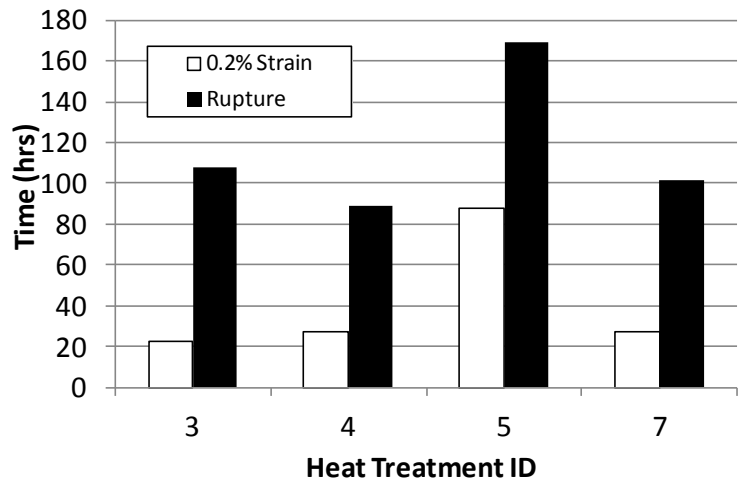

Figure: 11: Creep results for the heat treat study without homogenization, tested at $704^{\circ} \mathrm{C}\left(1300^{\circ} \mathrm{F}\right)$ and $586 \mathrm{MPa}(85 \mathrm{ksi})$.

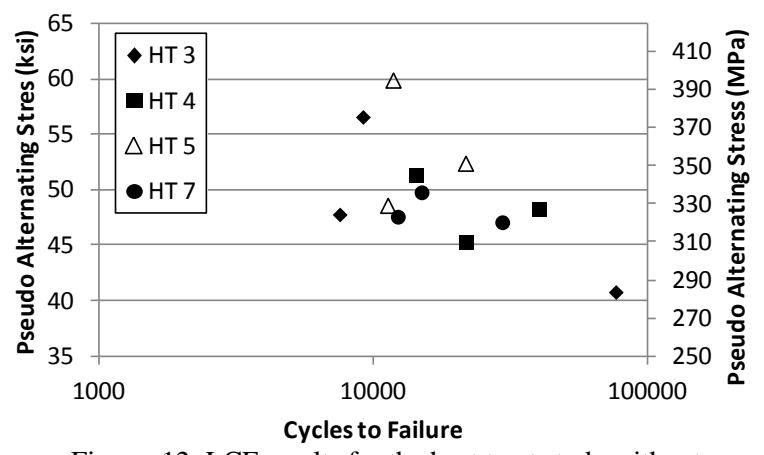

Figure: 12: LCF results for the heat treat study without homogenization.

\section{Detailed Mechanical Property Assessment}

Results from various tests are shown in the subsequent Figures (Figures 13-19 and Table 6). Although no direct comparisons are shown with OEM design database values, the authors concluded that the detailed mechanical property evaluation results indicate that the properties are better than cast 718 by approximately $42^{\circ} \mathrm{C}$ $\left(75^{\circ} \mathrm{F}\right)$, or more. Where possible, results are compared with MMPDS and cast alloy 718 specification (AMS5383) data. A summary of the results is provided:

- The tensile properties are adequate for OEM requirements up to $704^{\circ} \mathrm{C}\left(1300^{\circ} \mathrm{F}\right)$ and thermal stability up to $732^{\circ} \mathrm{C}\left(1350^{\circ} \mathrm{F}\right)$.

- Notched creep bar testing is typically not performed on cast alloys. In fact, there currently is not such a requirement for cast Alloy 718 (AMS5383). However, the intention of the mechanical test matrix was to perform a wide range of tests to provide a basis for further investigation. As indicated in Figure 15, the results are primarily gage failures without any correlation with $\mathrm{k}_{\mathrm{t}}$, indicating that the notch and gage failures are representative of cast product with large grains ( 2 to 4 grains in the fracture surface).

- Notched creep, fatigue crack growth rate, and fracture toughness results are typical of coarse-grain superalloys. 
- The thermal stability evaluation concluded shows that a slight loss of strength and increase in ductility occurs after exposures at $760^{\circ} \mathrm{C}\left(1400^{\circ} \mathrm{F}\right)$ (Figure 13). The results are typical of coarse-grain superalloys.

- Fractography indicated that the HCF initiation sites are predominantly grain facets at the surface.
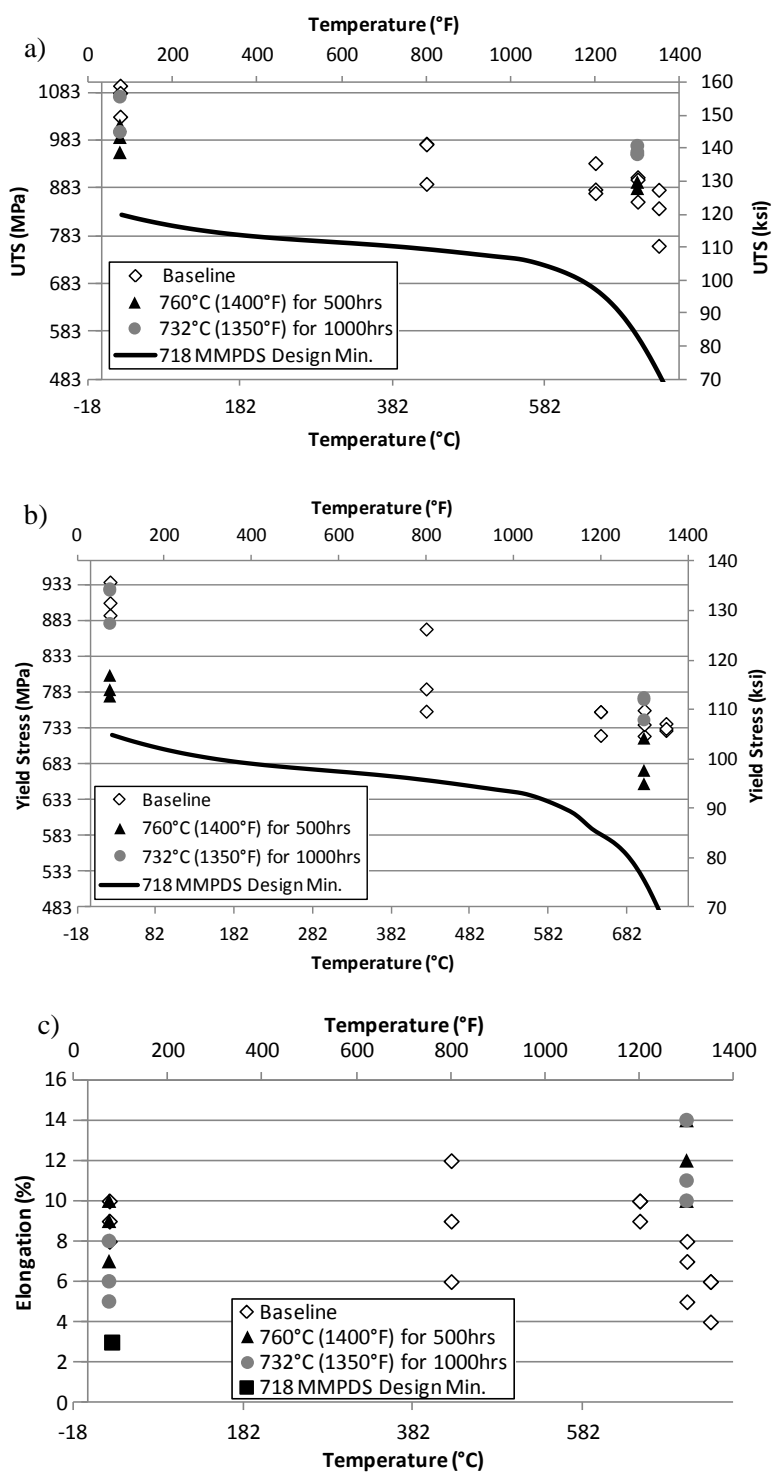

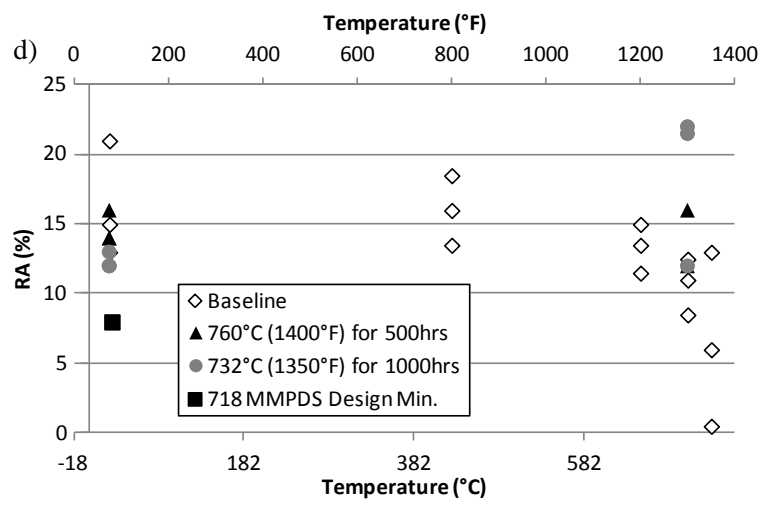

Figure 13: Detailed mechanical testing tensile results (a) UTS, (b) yield stress, (c) elongation, and (d) reduction in area [3].

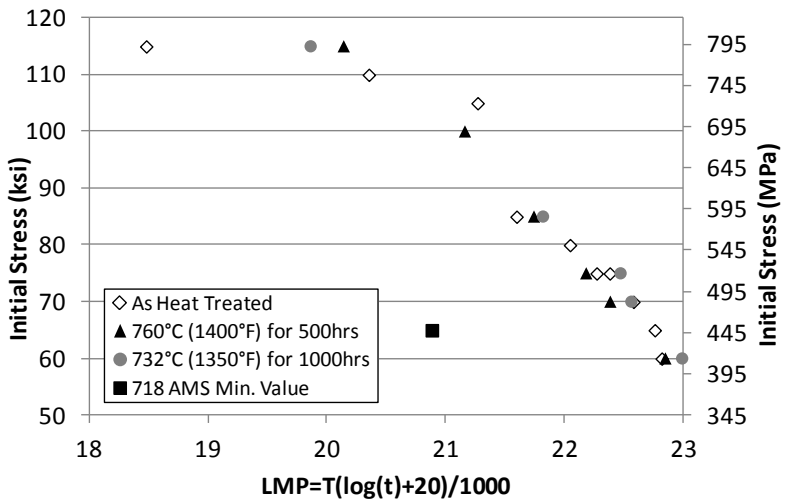

Figure 14: Detailed mechanical testing creep results: LarsenMiller plot to fracture ( $\mathrm{T}$ is in Kelvin and $\mathrm{t}$ is in hours) [4].

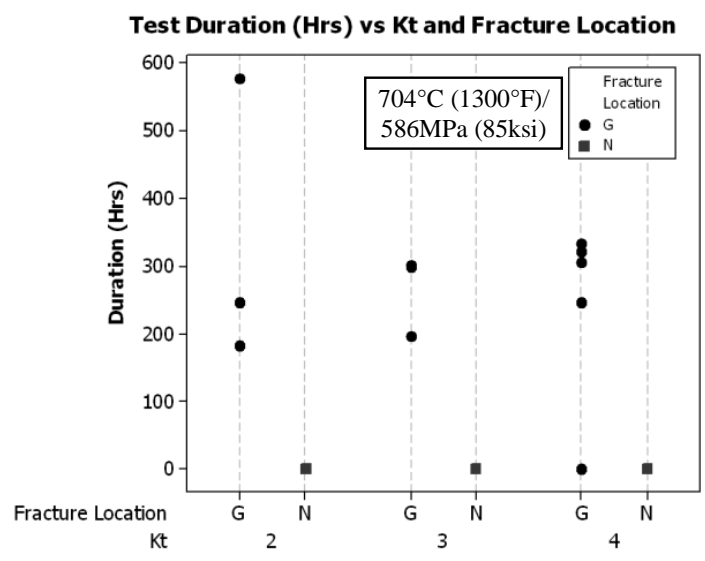

Figure 15: Detailed mechanical testing creep combo bar results as a function of $\mathrm{k}_{\mathrm{t}}$. (ASTM E292). 


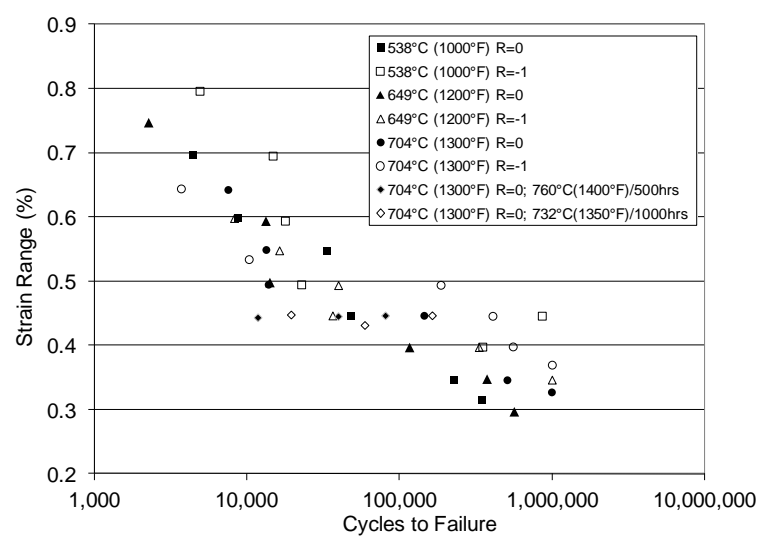

Figure 16: Detailed mechanical testing smooth bar LCF results; strain range $(\%)$ versus cycles.

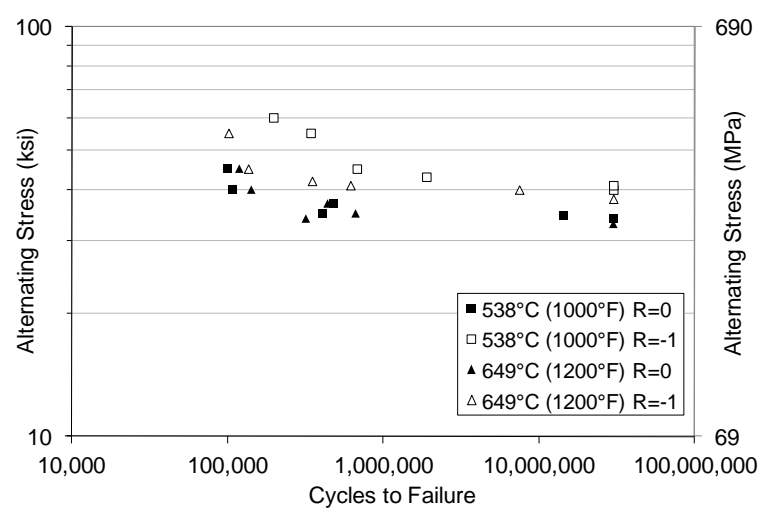

Figure 17: Detailed mechanical testing smooth bar HCF results; alternating stress versus cycles.

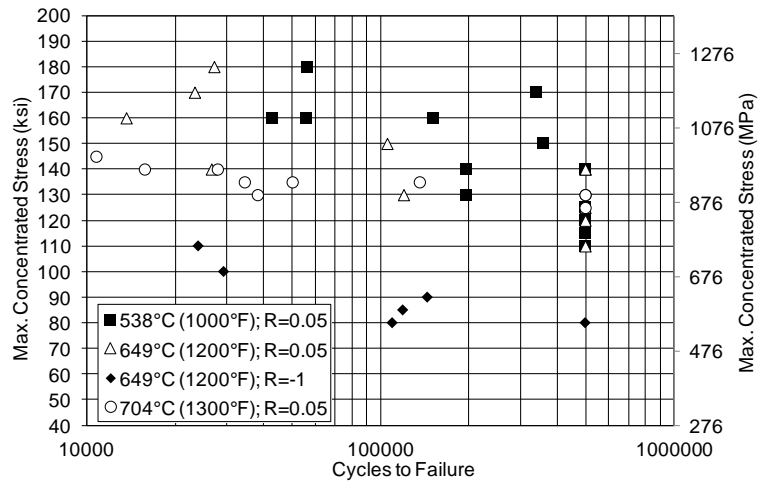

Figure 18: Detailed mechanical testing notched bar LCF results; maximum concentrated stress versus cycles $\left(k_{t}\right.$ of 2$)$.

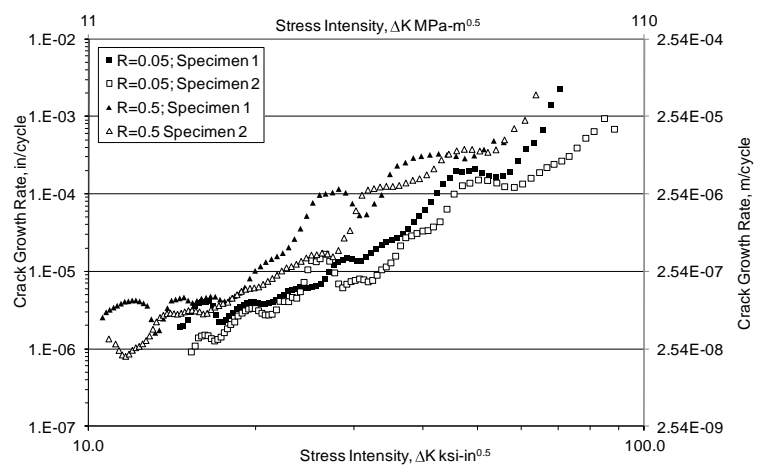

Figure 19: Detailed mechanical testing fatigue crack growth rate results. Testing performed at $649^{\circ} \mathrm{C}\left(1200^{\circ} \mathrm{F}\right)$.

Table 6: Detailed mechanical testing fracture toughness results (ASTM E399).

\begin{tabular}{|c|c|}
\hline Temperature, ${ }^{\circ} \mathbf{C}\left({ }^{\circ} \mathbf{F}\right)$ & $\mathbf{K q}, \mathbf{M P a}[\mathbf{m}]^{\wedge} \mathbf{0 . 5}\left(\mathbf{k s i}[\text { in. }]^{\wedge} \mathbf{0 . 5}\right)$ \\
\hline Room & $106.7(97.1)$ \\
\hline Room & $89.8(81.7)$ \\
\hline Room & $93.4(85)$ \\
\hline $538(1000)$ & $81.3(74)$ \\
\hline $538(1000)$ & $76.8(69.9)$ \\
\hline $704(1300)$ & $78.3(71.3)$ \\
\hline
\end{tabular}

\section{$\underline{\text { Weld Repair Process Development }}$}

Results of the implemented weld process are shown in Figure 20 Welding after casting and before HIP, solution, and age yielded the least number of indications. The optimized parameters were then implemented into a weld mechanical test ring geometry that was heat treated after welding (Figure 21). Tensile, creep, and LCF were performed on various conditions, including the weld, partial weld, and the base alloy, which were all compared with baseline values from the detailed mechanical testing effort (Figures 22-24). The results indicated that there is not a distinguishable debit to tensile or LCF properties. There is slight decrease in creep resistance that is attributed to the locally reduced grain size of the weld zone.
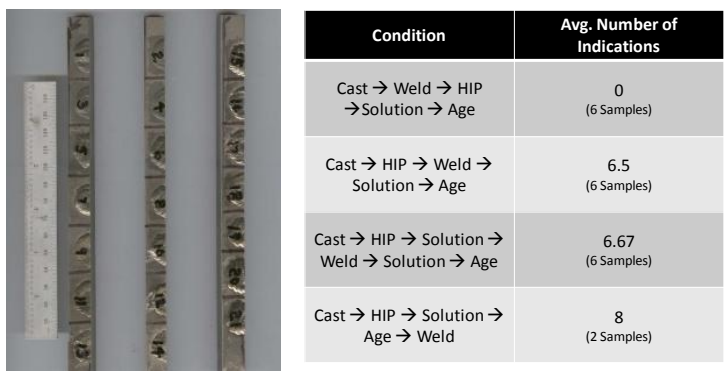

Figure 20: Average number of indications witnessed at various heat treatment conditions. 


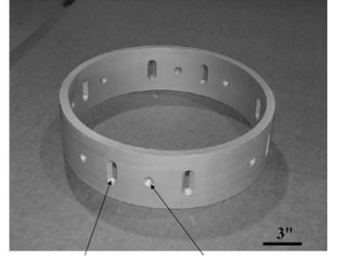

Locations for full \& partial

a) thickness welds

\begin{abstract}
b)
\end{abstract}

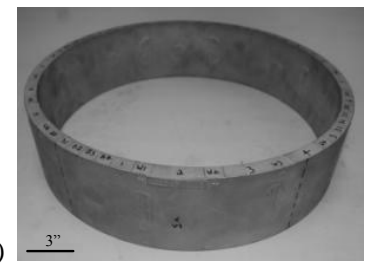

Figure 21: Weld mechanical test ring (a) prior to welding and (b) post weld and heat treat.
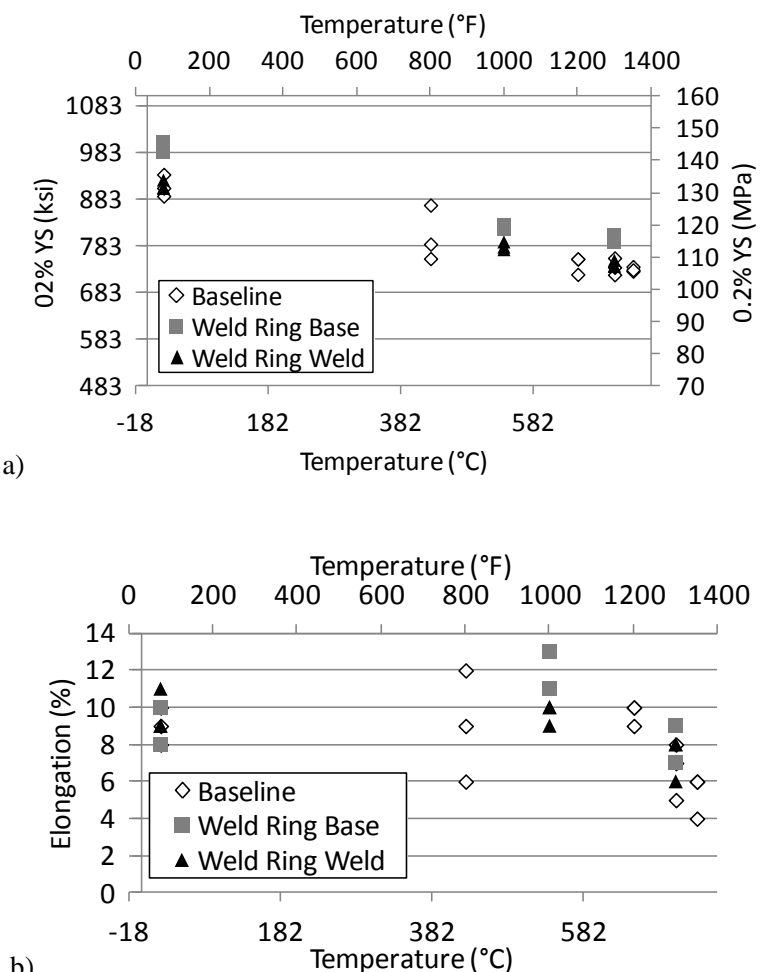

Figure 22: Weld ring mechanical testing tensile results (a) yield stress and (b) elongation.

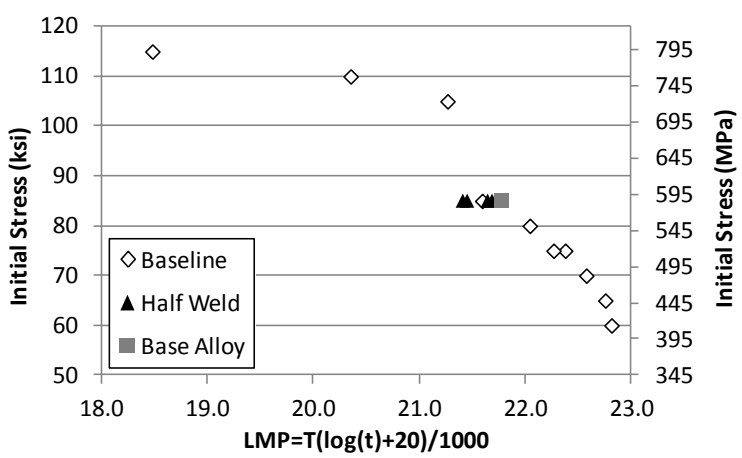

Figure 23: Weld ring mechanical testing creep rupture ( $\mathrm{T}$ is in Kelvin and $\mathrm{t}$ is hours).

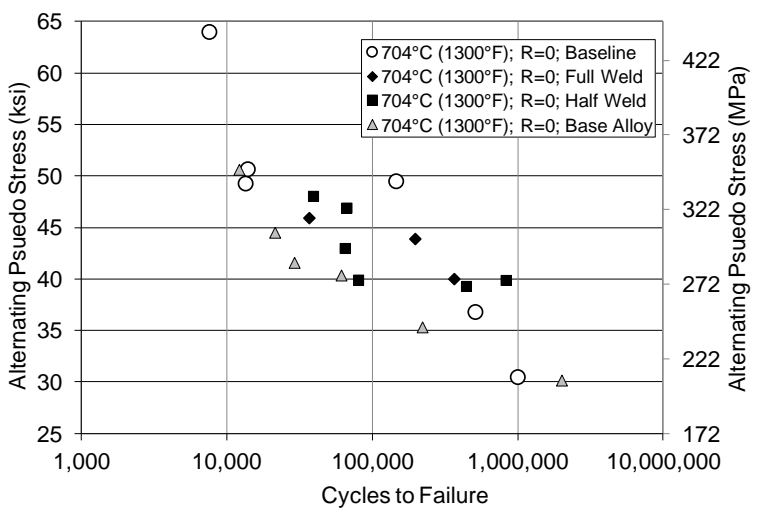

Figure 24: Weld ring mechanical testing LCF results.

\section{Cast Part Validation}

The OEM components were cast successfully. Basic evaluations revealed that parts cast in 718Plus alloy, (1) can be cast using standard manufacturing processes, (2) may not require new tooling (depends on the part and tolerances), and (3) performs very well as a cast alloy.

\section{Conclusion}

- A cast ATI 718Plus® alloy heat treatment cycle was chosen for further development.

- A chosen homogenization treatment was eliminated because of the negative effect on mechanical properties, such as high temperature ductility.

- Results from the detailed mechanical properties assessment indicate that the elevated temperature improvement goal of $42^{\circ} \mathrm{C}\left(75^{\circ} \mathrm{F}\right)$ has been met or exceeded. Also, no significant debits in mechanical properties were found in the extended mechanical property, partial and full weld, or the thermal stability evaluations.

- $\quad$ ATI 718Plus® alloy parts were successfully cast.

\section{Acknowledgments}

The authors would like to acknowledge partial funding support for this effort under the U.S. Air Force Metals Affordability Initiative program, agreement no. FA8650-06-2-5211, as well as collaborative efforts under this MAI project between ATI Allvac, GE, Honeywell Aerospace, PCC Structurals, Pratt \& Whitney, and Rolls-Royce.

\section{References}

1. R. L. Kennedy, "Allvac ${ }^{\circledR} 718$ Plus ${ }^{\mathrm{TM}}$, Superalloy for the Next Forty Years." Superalloys 718, 625, 706 and Derivates 2005, p.1. E. A. Loria, ed. TMS 2005.

2. Peterson, BH, Krishnan, V, et al. "Castability of 718Plus for Structural Gas Turbine Engine Components," 7th International Symposium on Superalloy 718 \& Derivatives. TMS, 2010.

3. MMPDS-05. Battelle Memorial Institute. p. 6-57. April 2010.

4. AMS 5383E. Aerospace Material Specification. SAE Aerospace. Revised May 2007. 